\title{
A DISCIPLINA LEGAL DO DIREITO À PRIVACIDADE NO ATUAL CONTEXTO DO MEIO AMBIENTE DIGITAL
}

\author{
THE LEGAL DISCIPLINE OF THE RIGHT TO PRIVACY BEFORE THE CURRENT \\ DIGITAL ENVIRONMENT CONTEXT
}

\author{
Paulo Antônio Grahl Monteiro de Castro*1 \\ Luciano Costa Miguel**2
}

\begin{abstract}
RESUMO A doutrina brasileira já reconhece a existência de um meio ambiente digital. Nesse contexto, justifica-se a presente pesquisa ante a relevância do direito à privacidade nesse âmbito. Pretende-se analisar a suficiência, ou não, da disciplina legal infraconstitucional, que visa à proteção da privacidade no ambiente digital. Para tanto, será procedida uma análise bibliográfica, por meio de uma abordagem qualitativa, extraída de uma pesquisa exploratória e descritiva, mediante o método hipotético-dedutivo. Conclui-se no sentido da insuficiência do regramento legal brasileiro, considerando-se o pouco detalhamento do tema e a indeterminação dos conceitos legais constantes no Marco Civil da Internet e na Lei Geral de Proteção de Dados Pessoais.
\end{abstract}

PALAVRAS-CHAVE: Privacidade; Direito de personalidade; Internet; Meio ambiente digital; Proteção legal.

\begin{abstract}
Brazilian doctrine already recognizes the existence of a digital environment. In this context, the present research is justified before a guarantee of the right to privacy in this context. It is intended to analyze the sufficiency, or not, of the infraconstitutional legal discipline, which aims to protect privacy in the digital environment. For that, a bibliographic analysis will be carried out, through a qualitative approach, extracted from an exploratory and descriptive research, through the hypothetical-deductive method. It concludes in the sense of the insufficiency of the Brazilian legal regulation, considering the little detail of the theme and
\end{abstract}

\footnotetext{
1 Doutorando e Mestre em Direito pela Escola Superior Dom Helder Câmara. Bacharel em Direito pela Universidade Federal de Minas Gerais. Especialista em Advocacia Pública pela Universidade de Coimbra, em parceria com o Instituto Democrático, e em Direito Penal e Processual Penal, pela Universidade Gama Filho. Pósgraduando em Mediação, Conciliação e Arbitragem pelo Instituto Democrático em parceria com a Faculdade Arnaldo. Professor do curso de Graduação em Direito da Escola Superior Dom Helder Câmara. Advogado. Procurador do Município de Belo Horizonte. E-mail: paulo_monteiro@terra.com.br

${ }^{2}$ Doutorando e Mestre em Direito pela Escola Superior Dom Helder Câmara. Pós-graduado em Direito Tributário pela Universidade Anhanguera-Uniderp. Professor do curso de Graduação em Direito da Escola Superior Dom Helder Câmara. Procurador da Fazenda Nacional. E-mail: lucianocmiguel@ hotmail.com
} 
the indeterminacy of the legal concepts contained in the Marco Civil da Internet and in the General Law for the Protection of Personal Data.

KEYWORDS: Privacy; Personality right; Internet; Digital environment; Legal protection.

\section{SUMÁRIO}

1 INTRODUÇÃO 2 O MEIO AMBIENTE DIGITAL E O SEU ATUAL CONTEXTO. 3 O DIREITO À PRIVACIDADE COMO DIREITO DA PERSONALIDADE. 4 OS DESAFIOS DA PRIVACIDADE NO CONTEXTO DO CAPITALISMO CONEXIONISTA. 5 A DISCIPLINA LEGAL PROTETIVA DA PRIVACIDADE NO MEIO AMBIENTE DIGITAL. 6 CONSIDERAÇÕES FINAIS. REFERÊNCIAS BIBLIOGRÁFICAS

\section{INTRODUÇÃO}

Em que pese o movimento de ampla conexão digital dos últimos anos que se potencializou, sobretudo, com o advento e a popularização das chamadas "redes sociais" e dos "smartphones", as pessoas ainda não possuem a compreensão de que o meio ambiente digital não se afigura uma dimensão separada do meio ambiente físico.

Lado outro, diante de peculiaridades ínsitas ao meio ambiente digital, não se pode descurar da necessidade de que se faça presente um arcabouço normativo que se revele próprio e específico para o seu contexto, sob pena de a proteção aos direitos da personalidade, dentre eles o atinente à privacidade, restar insuficiente em sua finalidade de cessar a ameaça ou a lesão, além de não garantir a indenização por perdas e danos ou mesmo outras sanções, conforme prescreve o art. 12 do Código Civil.

Nesse caminho, é inegável já terem acontecido avanços, na medida em que o Brasil passou de um cenário de uma quase completa anomia, no que diz respeito à questão específica da privacidade no meio ambiente digital (porquanto inexistia, até há pouco tempo, disciplina específica referente ao assunto) para um panorama em cujo bojo, hoje, já são identificáveis importantes diplomas legislativos, tais como a Lei Federal n. 12.965/2014 (Marco Civil da Internet) e a Lei Federal n. 13.709/2018 (Lei Geral de Proteção de Dados Pessoais), a última, ainda, com alguns dispositivos em período de vacatio legis.

No presente trabalho, objetiva-se analisar a questão da privacidade, nesse atual contexto do meio ambiente digital, ou, mais especificamente falando, da privacidade nos meios digitais, analisando se a disciplina legal brasileira se revela suficiente na proteção do referido 
direito, mormente diante de um contexto no qual se faz presente uma evidente e constante tensão, ou se ainda haveria lacunas aptas a gerar um cenário de insegurança jurídica e mesmo de potencial falta de proteção ao referido direito?

Para tanto, proceder-se-á a uma análise bibliográfica, envolvendo não somente textos focados no aspecto jurídico, como, também, nos aspectos sociológicos e tecnológicos relacionados à temática em apreço. A abordagem do tema será qualitativa, extraída de uma pesquisa exploratória e descritiva, mediante o método hipotético-dedutivo, utilizando-se de análise de bibliografia e de documentos legislativos que versam sobre o problema.

Para que se possa responder, devidamente, a esse problema, revela-se importante perceber que as potenciais ofensas à privacidade, no meio ambiente digital, vêm se intensificando, na medida em que a disponibilização de dados pessoais, no espaço virtual, transformou-se em prática corriqueira e, muitas vezes, até despercebida.

\title{
2 O MEIO AMBIENTE DIGITAL E O SEU ATUAL CONTEXTO
}

A doutrina se refere, com razoável frequência, ao chamado meio ambiente digital, na medida em que o art. $3^{\circ}$ da Lei Federal n. 6.938/1981 cria um espaço positivo de incidência da norma, que desvela um conceito jurídico indeterminado, tal como tem prelecionado Celso Antônio Pacheco Fiorillo (2014, p. 73).

Ainda segundo Fiorillo (2014, p. 81), o meio ambiente digital se afigura como uma espécie do meio ambiente dito cultural. Vejamos:

\begin{abstract}
O meio ambiente cultural por via de consequência se revela no século XXI em nosso País exatamente em face de uma cultura que passa por diversos veículos reveladores de um novo processo civilizatório adaptado necessariamente à sociedade da informação, a saber, de uma nova forma de se viver relacionada a uma cultura de convergência em que as emissoras de rádio, televisão, o cinema, os videogames, a Internet, as comunicações através de ligações de telefones fixos e celulares, etc. moldam uma "nova vida" reveladora de uma nova faceta do meio ambiente cultural, a saber: o meio ambiente digital.
\end{abstract}

Todavia, essa reflexão merece o devido aprofundamento, na medida em que, na sociedade atual, revela-se altamente dificultoso estabelecer uma fronteira entre o meio ambiente digital e, por oposição, ao meio ambiente que não seria digital.

Nesse sentido, aliás, merece especial menção o ensinamento de Marcelo Kokke Gomes e Márcio Luís de Oliveira (2018, p. 63), que entendem que o meio ambiente virtual 
(digital) e o não digital (físico) são, em verdade, inseparáveis, porquanto: "The virtual environment cannot be totally disconnected from the physical one once the virtual world is conceived and also unveiled in the real (physical and cultural) world"3.

Partindo-se dessa perspectiva, há de ser destacado que a referência ao chamado meio ambiente virtual ou digital se presta, muito mais, a uma limitação didática do espectro da presente pesquisa do que a qualquer outro propósito, justamente na medida em que referida fronteira, a cada dia que passa, tem contornos menos visíveis.

Enquanto, no Brasil, num momento em que o sistema global de redes de computadores interligadas, conhecido como Internet, começava a se popularizar, as maiores ofensas à privacidade derivavam dos indesejáveis "spams", hoje, de outro lado, o que se constata é que as referidas ofensas vêm se intensificando em ritmo acentuado, o que se comprova, principalmente, a partir do fenômeno da publicidade direcionada.

Aquela prática tão deletéria, de envio, em massa, de mensagens de correio eletrônico, com finalidades várias, inclusive publicitárias, transmudou-se em conduta claramente mais agressiva, consistente na utilização dos dados pessoais fornecidos com o propósito de oferecimento de uma publicidade direcionada.

Segundo Tiago Agostinho de Almeida (2010, p. 9):

Simultaneamente ao desenvolvimento e a popularização da Internet e do e-mail, ocorreu o crescimento de um fenômeno que, desde o seu surgimento, tornou-se um dos principais problemas da comunicação eletrônica em geral: o envio em massa de mensagens não-solicitadas. Esse fenômeno ficou conhecido como spamming, as mensagens em si como spam e os seus autores como spammers (Gyöngyi \& GarciaMolina, 2005).

Tiago Agostinho de Almeida (2010, p. 10) explica, ainda, que "spam” é expressão que também deriva de "spiced ham", uma espécie de presunto temperado, enlatado, que se tornou uma das principais fontes de alimento em meio à Segunda Guerra Mundial, na medida em que se tratava de alimento que não estava entre os produtos sujeitos a racionamento na Inglaterra.

Em um conhecido esquete do grupo "Monty Python", fez-se piada com a situação acima, consistente no fato de um casal ter comparecido a uma lanchonete, casal esse que,

\footnotetext{
${ }^{3}$ Em tradução livre: O meio ambiente virtual não pode ser totalmente desconectado do meio ambiente físico, na medida em que o mundo virtual é concebido e também revelado no mundo real (físico e cultural).

${ }^{4}$ Do acrônimo "sending and posting adverstisement in mass", que se refere aos e-mails endereçados em massa sem qualquer tipo de solicitação dos destinatários.
} 
quando indaga quais as refeições disponíveis, é informado de que todas elas contêm, de alguma maneira, o referido ingrediente ("spam"). Em um dado momento do referido esquete, vários "vikings" começam a cantar, de forma irritante, recitando, repetidamente, o termo "spam", e impedindo, até mesmo, que pudesse haver algum tipo de comunicação exitosa.

Basicamente, referido esquete retratou muito bem o que ocorre com o fenômeno do “spam”: mensagens não solicitadas, em grande número, enviadas, via correio eletrônico, e que perturbam, sobremaneira, a comunicação produtiva, na medida em que se misturam às outras mensagens que são, de fato, relevantes, dificultando a análise e o tratamento das últimas.

Tiago Agostinho de Almeida (2010, p. 10-11) explica, em sua tese, que o primeiro registro que se tem de mensagem não solicitada, de natureza comercial, diz respeito à publicidade de um computador, o "DECSYSTEM-20”, no ano de 1978.

De lá para cá, houve franca expansão desse tipo de prática deletéria, a qual, em verdade, acabou por evoluir. Fala-se em evolução, nesse ponto, na medida em que aquelas mensagens de correio eletrônico, que, antes, eram disparadas sem que pudessem mirar, de forma precisa, algum alvo, passaram, agora, a ser direcionadas.

Como poderia, contudo, haver esse direcionamento? Esse direcionamento se mostrou possível, sobretudo, a partir do avanço das técnicas de coleta de dados no meio ambiente digital, dados esses que, muitas vezes, acabam por ser fornecidos, ora de modo espontâneo, ora de modo não tão espontâneo, pelos próprios usuários, sendo, até mesmo, apreendidos a partir de comportamentos deste no uso de redes sociais e de aplicativos em geral.

No Brasil, essa disponibilização de informações, cada vez maior, nos meios digitais, passou a ser sentida, de forma mais clara, a partir do advento, por exemplo, da primeira rede social a aqui se popularizar, o "Orkut".

Com o passar do tempo, não só foram se popularizando, por aqui, outras redes sociais (tais como o "Facebook", o "Instagram", o "TikTok" e, até o "Waze”), como, também, simultaneamente, o uso de "smartphones", os quais são utilizados, diuturnamente, para as finalidades mais variadas possíveis (como trabalho, lazer, comunicação, educação, entre outras) e que têm enorme potencial de captação de dados pessoais.

Nesse ponto, uma conduta bastante simples pode demonstrar a situação em referência: basta que o usuário de uma rede social faça, por exemplo, uma busca a respeito de parques temáticos da "Disney", para, imediatamente, surgirem, em sua navegação corriqueira, anúncios referentes a passagens aéreas para os Estados Unidos. Isso pode ser percebido nas 
próprias redes sociais, em plataformas como o "Youtube", e, até mesmo, na própria caixa de correio eletrônico.

Desse atual e grave contexto, em que as pessoas estão cada vez mais sujeitas a terem sua privacidade invadida, é que exsurge a justificativa e o respectivo problema objeto do presente artigo.

\section{O DIREITO À PRIVACIDADE COMO DIREITO DA PERSONALIDADE}

Os chamados direitos da personalidade têm natureza existencial, não podem ser destacados da pessoa de seu titular e derivam, sobretudo, da própria noção de dignidade humana. Dada a sai importância, na dicção do art. 11 do Código Civil: “Com exceção dos casos previstos em lei, os direitos da personalidade são intransmissíveis e irrenunciáveis, não podendo o seu exercício sofrer limitação voluntária."

Segundo lições de Bruno Torquato de Oliveira Naves e Maria de Fátima Freire de Sá (2017, p. 18), “Direitos da personalidade são aqueles que têm por objeto os diversos aspectos da pessoa humana, caracterizando-a em sua individualidade e servindo de base para o exercício de uma vida digna".

Embora possam ter reflexos patrimoniais, os direitos da personalidade vêm sendo apontados pela doutrina majoritária como sendo direitos subjetivos de natureza existencial. Nada obstante, Bruno Torquato de Oliveira Naves (2010, p. 147) já aponta, há muito, que "Não se pode, nem mesmo, afirmar que os 'direitos' de personalidade são sempre direitos subjetivos. Podem sê-lo, mas também podem ocupar outras situações jurídicas”.

Isso, pois, conforme o seu ensinamento (2010, p. 48):

\footnotetext{
Dentro dessas "situações jurídicas da personalidade", os dados genéticos podem apresentar-se como direito subjetivo, dever jurídico, faculdade, direito potestativo, sujeição, ônus e poder. Será o caso conformado pelo Direito, porém não só pelo Direito dos enunciados normativos do positivismo, mas pelo Direito construído argumentativamente, tendo em vista tais enunciados normativos.
}

Altamente pertinente, no ponto, a referida observação, na medida em que os direitos na personalidade não se encaixam, sempre, na ideia de direito subjetivo, podendo assumir, em vários momentos, outras feições, tais como as acima apontadas. 
A respeito, especificamente, da privacidade, temos que se trata, indubitavelmente, de bem jurídico protegido não só no plano legal, como, também, no plano constitucional. $\mathrm{O}$ art. $5^{\circ}, \mathrm{X}$, da CRFB/1988, é expresso em estabelecer que "são invioláveis a intimidade, a vida privada, a honra e a imagem das pessoas, assegurado o direito a indenização pelo dano material ou moral decorrente de sua violação".

À proteção constitucional, somam-se, ainda, as proteções constantes da legislação infraconstitucional, com destaque, em geral, para diplomas como o Código Civil ${ }^{5}$ e o Código de Proteção e Defesa do Consumidor ${ }^{6}$, e, em específico, para a Lei Federal n. 12.965/2014 (Marco Civil da Internet) e para a Lei Federal n. 13.709/2018 (Lei Geral de Proteção de Dados Pessoais - LGPD).

Como se pode perceber, no Brasil, em se tratando de proteção de direitos de personalidade no meio ambiente digital, até recentemente, havia disciplina legal bastante reduzida, situação que foi, certamente, amenizada a partir de 2014, com o advento do Marco Civil da Internet, bem como, posteriormente, da Lei Geral de Proteção de Dados Pessoais (que, embora ainda esteja em período de vacatio legis, virá, em breve, a melhor regulamentar questões atinentes ao objeto do presente trabalho).

Aliás, os próprios direitos da personalidade são, cronologicamente, mais recentes no Direito privado, do que a própria noção de personalidade, tal como apontado por Bruno Torquato de Oliveira Naves e Maria de Fátima Freire de Sá (2017, p. 18), o que se potencializa, no caso específico do meio ambiente digital, na medida em que se trata de contexto mais específico e ainda mais recente.

Lado outro, seriam referidas leis, realmente, suficientes para cuidar de um assunto tão complexo e, de certo, tão dinâmico? É o que será analisado no momento oportuno.

\section{OS DESAFIOS DA PRIVACIDADE NO CONTEXTO DO CAPITAlisMo CONEXIONISTA}

\footnotetext{
${ }^{5}$ Com destaque ao seu art. 21, que assim dispõe: "A vida privada da pessoa natural é inviolável, e o juiz, a requerimento do interessado, adotará as providências necessárias para impedir ou fazer cessar ato contrário a esta norma." Digno de registro que esse artigo foi declarado inconstitucional, pela técnica da inconstitucionalidade sem redução de texto, no julgamento da $\mathrm{ADI} \mathrm{n}^{\circ} 4815$, para que seja dispensada a autorização para a escrita de biografias. ${ }^{6}$ Com destaque para os seus arts. 36 a 38 que tratam da publicidade abusiva e os arts. 43 e 44 que regulamentam os bancos de dados e cadastros de consumidores.
} 
No Brasil, e, até, no mundo, a popularização do acesso à Internet iniciou-se na década de 1990, no que se tem chamado, comumente, de "boom" da Internet.

A esse respeito, Tiago Agostinho de Almeida (2010, p. 7) aponta que "O crescente interesse mundial aliado a interesse comercial, que evidentemente observa o potencial financeiro e rentável da Internet, proporcionou o boom e a popularização da Internet na década de 90". Foi nessa época que a referida rede, que, antes, era quase que restrita a ambientes acadêmicos, passou a alcançar, também, de maneira mais ampla, os usuários ditos domésticos.

Com o processo de popularização da Internet, que trouxe inegáveis benefícios para a sociedade, acabaram por vir, também, alguns desafios a serem solucionados, dentre os quais a já mencionada questão do fenômeno do "spam".

Para se ter uma ideia da dimensão do problema, no ano de 1998, um caso de "spam", que chegou, devidamente traduzido, ao Brasil, tornou-se bastante célebre. Começou a circular, àquela época, via correio eletrônico (“e-mail”), um boato no sentido de que xampus que contivessem "lauril sulfato de sódio" seriam cancerígenos, tal como narra Karen C. Daly (2000).

Muitas pessoas, acreditando na história, deixaram de consumir produtos que contivessem o referido elemento químico, passando a utilizar produtos de concorrentes que não o tivessem presente em suas fórmulas.

Talvez esse tenha sido, no Brasil, um dos primeiros grandes casos de boatos (conhecidos como "hoaxes") que circularam por meio de mensagens de correio eletrônico não solicitadas, em situação que poderia ser tida, também, como uma das grandes precursoras do fenômeno das chamadas "fake news" (notícias falsas), as quais, contudo, por não serem objeto deste trabalho, não serão abordadas com maior profundidade.

Segundo Bruno Torquato de Oliveira Naves e Maria de Fátima Freire de Sá (2017, p. 95), “a vida privada é o gênero no qual se encontra a expressão da individualidade do ser humano e envolve a preservação de aspectos particulares contra a intromissão indevida da sociedade, do Estado ou de outros particulares". Nesse sentido, o direito à privacidade protege o indivíduo contra a intromissão indevida de onde quer que ela parta, seja do Estado, seja, inclusive, dos particulares.

Lado outro, referidos autores pontuam (2017, p. 97) que:

Outras vezes dados de pessoas diversas são disponibilizados, ou mesmo comercializados, a determinadas entidades para construção de perfis de consumo 
identificando seus hábitos e preferências. A disponibilização de dados pessoais pode não representar uma violação de privacidade, porque a todo momento, voluntariamente, permitimos que vários dados sejam veiculados. A lesão deve ser configurada casuisticamente.

(...)

Retornando ao tema da inviolabilidade, é importante destacar que os limites da vida não são inflexíveis. A livre formação da personalidade e a autonomia privada atuam de maneira a possibilitar determinadas formas de exposição da privacidade e da intimidade das pessoas. Prova disso é a veiculação de programas televisivos cuja possibilidade jurídica se dá no âmbito da autonomia pessoal, por meio da realização de negócios jurídicos, normalmente de forma onerosa, com o objetivo de exibir a vida privada ao público, observando-se certos limites.

Não restam grandes dúvidas, realmente, no sentido de que a eventual lesão ao direito de privacidade deva ser apurada de forma casuística, levando em consideração as circunstâncias do caso concreto.

Contudo, quais seriam os parâmetros para que essa eventual violação fosse apurada? Haveria alguma objetividade, do ponto de vista legal? Ou haveria o risco de a conclusão, seja no sentido de sua violação, seja no sentido de sua não violação, ser tomada de modo pouco técnico e arbitrário?

A verdade é que, no contexto em que vivemos, de um capitalismo conexionista (em cujo bojo as conexões entre pessoas, sobretudo no meio virtual, se intensificam de forma cada vez mais evidente), tantos são os dados que são fornecidos (ou, até, captados), no meio virtual, que, muitas vezes, nem nos damos conta dessa dimensão. É absolutamente natural, aliás, em meio ao referido contexto, que o usuário "baixe sua guarda" no cotidiano de sua navegação nos meios virtuais.

Mariana Zanata Thibes (2014, p. 9), nesse ponto, empreendendo uma análise sociológica, chega a afirmar a privacidade como uma forma cujo conteúdo parece estar se esvaziando. Referida autora (2014, p. 139-140) aponta, ainda, de maneira bastante preocupante, o seguinte:

As chamadas "tecnologias de controle da identidade" (identity management), compostas por uma série de mecanismos que pretendem autenticar os indivíduos em vários contextos, tais como reconhecimento facial, scanner corporal, marcas digitais, etc, tornaram-se operação corriqueira dos modos de governança e de práticas comerciais. Serviços online tentam, a todo momento, capturar a autenticidade dos indivíduos: o Google, exigindo informações reais, seja para assegurar a veracidade da identidade dos usuários, seja para determinar com mais precisão o seu perfil, e o mesmo acontece com outras empresas que oferecem esse tipo de serviço. O problema que a autenticação traz para a vida social fica mais claro quando o perfil criado pelas empresas ou governos é não apenas distinto do que gostaríamos de revelar, mas serve como forma de controle e segregação social. As tecnologias de autenticação e coleta 
de dados, seja por operações de segurança ou por meio da CRM - "customer relationship management" (gestão da relação com o cliente) criam cadastros sobre as pessoas e as posicionam em determinadas categorias sociais. Isso aparece, no mercado de consumo, por meio de "promoções exclusivas", descontos especiais, etc. Nas empresas de aviação, por exemplo, o preço de uma mesma categoria de voo pode variar muito de comprador para comprador, não sendo surpreendente que aqueles que pode viajar na primeira classe encontrem preços melhores do que os que viajam esporadicamente na classe econômica.

Igualmente célebre, e de conhecimento geral, é a frase de Mark Zuckerberg, para quem para quem “A privacidade não é mais uma norma social”, referenciada na obra de Paul Collier (2019, p. 45) e ali criticada, no sentido de que tal postura poderia consubstanciar a suplantação da sociedade espacialmente delimitada do Estado-nação.

Não há dúvidas que, nesse ponto, já é possível perceber como a invasão à privacidade se intensificou, ao longo dos últimos anos, na medida em que, enquanto, num passado bastante recente, o desrespeito parecia restringir-se a envio de mensagens eletrônicas não solicitadas ("spam"), hoje, pode-se perceber, de forma bastante clara, como a utilização de dados pessoais vem sendo usada, de forma absolutamente ampla, para o envio, por exemplo, de publicidade direcionada, explorando, não raras vezes, a vulnerabilidade social e emocional do consumidor.

Nesse sentido, Mariana Zanata Thibes (2014, p. 165-166), traça um histórico bastante elucidativo:

Desde os primórdios da chamada sociedade de consumo, as informações pessoais eram consideradas fundamentais pelos setores de marketing, para orientar suas ações e direcionar negócios. Entretanto, essas informações só poderiam ser custosamente obtidas por meio de estratégias tradicionais de pesquisa, que demandavam muitos recursos financeiros e, sobretudo, careciam de vasta mão-de-obra para serem realizadas. Ainda assim, com frequência, não era simples atingir o alvo: entender os desejos dos consumidores e direcionar as mercadorias para o público certo permanecia uma missão difícil. Com a popularização da Internet e, principalmente, das redes sociais, essas informações adquiriram novo fluxo: passaram a circular abundantemente em ambientes virtuais, além de serem constantemente renovadas, permitindo que desejos e tendências sejam mapeados com rapidez inédita e até mesmo antecipados de modo preciso. Desse modo, não à toa, tornaram-se a "galinha dos ovos de ouro" da publicidade e rapidamente dão ímpeto a um novo tipo de negócio e, já se tornou comum dizer, a uma nova forma de economia: a digital.

O novo modo de circulação, apreensão e troca de informações fez com que estas, subitamente, adquirissem "valor" para os proprietários das empresas online e passaram a ser, inclusive, comercializadas como qualquer outra mercadoria. 
Aquilo que, anteriormente, revelava-se bastante dificultoso (obtenção de informações referentes a padrões de consumo e assuntos congêneres), passou a se mostrar absolutamente abundante, a partir da possibilidade material quer da obtenção voluntária de dados, quer de captação destes mediante análise de comportamentos, em geral, assumidos no meio ambiente virtual, seja nas redes sociais, seja no próprio uso cotidiano de outras funcionalidades ínsitas à Internet.

Nesse sentido, estaria a legislação, especialmente a brasileira, preparada para lidar com as questões atinentes a esse efetivo conflito entre a privacidade e a sujeição ao fornecimento de dados pessoais como, muitas vezes, um requisito para a utilização de aplicativos e de redes sociais? É essa a análise que se propõe a fazer a seguir.

\section{A DISCIPLINA LEGAl PROTETIVA DA PRIVACIDADE NO MEIO AMBIENTE DIGITAL}

Como já adiantado, fazendo menção aos ensinamentos de Bruno Torquato de Oliveira Naves e Maria de Fátima Freire de Sá (2017, p. 18), a disciplina legal a respeito dos direitos da personalidade, tendo em vista, inclusive, serem de existência muito mais recente do que a noção de personalidade, acaba por se mostrar, em si, em boa medida, bastante reduzida.

Nesse ponto, conforme já adiantado, muito embora tenha a privacidade proteção expressa no plano constitucional (art. $5^{\circ}, \mathrm{X}$, da CRFB/1988), referida proteção ainda é pouco minudenciada no aspecto legal positivo propriamente dito.

Poder-se-ia considerar essa forma de disciplina, em específico, como salutar, na medida em que teria o potencial condão de consubstanciar uma maneira de prevenir o engessamento da lei, até porque, certamente, as relações sociais costumam se desenvolver de forma muito mais ágil e veloz do que o processo legislativo (que pressupõe, entre outras características, a burocracia que lhe é ínsita).

Nesse sentido, aliás, Miguel Reale, na sua "Visão Geral do Projeto de Código Civil" (2003, p. 40), menciona, em referência ao então Projeto de Código Civil, que não seria possível deixar de reconhecer, em nossos dias, a participação de valores éticos no ordenamento jurídico, com compatibilização às conquistas da técnica jurídica, no que se optou, muitas vezes, no referido diploma, por normas genéricas ou cláusulas gerais, “a fim de possibilitar a criação 
de modelos jurídicos hermenêuticos, quer pelos advogados, quer pelos juízes, para contínua atualização dos preceitos legais".

Muito embora referida técnica tenha, de fato, sua importância, e mereça, em certa medida, seus aplausos, deve-se dizer que, em termos de privacidade no contexto do meio ambiente digital, ainda se afigura sobremodo tímida a forma como o legislador optou por disciplinar o tema, seja no próprio Código Civil, seja, também, em diplomas como o Marco Civil da Internet e a Lei Geral de Proteção de Dados Pessoais, sendo que o legislador, nos dois últimos, valeu-se, em boa medida, daquela mesma lógica.

O Marco Civil da Internet (Lei n. 12.965/2014), por exemplo se restringe, basicamente, no que diz respeito à privacidade, às seguintes disposições consubstanciadas em somente três artigos:

Art. $3^{\circ}$ A disciplina do uso da internet no Brasil tem os seguintes princípios:

(...)

II - proteção da privacidade;

III - proteção dos dados pessoais, na forma da lei;

(...)

Art. $8^{\circ} \mathrm{A}$ garantia do direito à privacidade e à liberdade de expressão nas comunicações é condição para o pleno exercício do direito de acesso à internet.

Parágrafo único. São nulas de pleno direito as cláusulas contratuais que violem o disposto no caput, tais como aquelas que:

I - impliquem ofensa à inviolabilidade e ao sigilo das comunicações privadas, pela internet; ou

II - em contrato de adesão, não ofereçam como alternativa ao contratante a adoção do foro brasileiro para solução de controvérsias decorrentes de serviços prestados no Brasil.

(...)

Art. 11. Em qualquer operação de coleta, armazenamento, guarda e tratamento de registros, de dados pessoais ou de comunicações por provedores de conexão e de aplicações de internet em que pelo menos um desses atos ocorra em território nacional, deverão ser obrigatoriamente respeitados a legislação brasileira e os direitos à privacidade, à proteção dos dados pessoais e ao sigilo das comunicações privadas e dos registros.

$\S 1^{\circ} \mathrm{O}$ disposto no caput aplica-se aos dados coletados em território nacional e ao conteúdo das comunicações, desde que pelo menos um dos terminais esteja localizado no Brasil.

$\S 2^{\circ} \mathrm{O}$ disposto no caput aplica-se mesmo que as atividades sejam realizadas por pessoa jurídica sediada no exterior, desde que oferte serviço ao público brasileiro ou pelo menos uma integrante do mesmo grupo econômico possua estabelecimento no Brasil.

$\S 3^{\circ}$ Os provedores de conexão e de aplicações de internet deverão prestar, na forma da regulamentação, informações que permitam a verificação quanto ao cumprimento da legislação brasileira referente à coleta, à guarda, ao armazenamento ou ao tratamento de dados, bem como quanto ao respeito à privacidade e ao sigilo de comunicações. 
$\S 4^{\circ}$ Decreto regulamentará o procedimento para apuração de infrações ao disposto neste artigo.

Já a Lei Geral de Proteção de Dados se restringe, quanto ao tema, basicamente, aos seguintes dispositivos materializados em não mais que cinco artigos:

Art. $1^{\circ}$ Esta Lei dispõe sobre o tratamento de dados pessoais, inclusive nos meios digitais, por pessoa natural ou por pessoa jurídica de direito público ou privado, com o objetivo de proteger os direitos fundamentais de liberdade e de privacidade e o livre desenvolvimento da personalidade da pessoa natural.

Parágrafo único. As normas gerais contidas nesta Lei são de interesse nacional e devem ser observadas pela União, Estados, Distrito Federal e Municípios. (Incluído pela Lei no 13.853, de 2019)

(...)

Art. $2^{\circ}$ A disciplina da proteção de dados pessoais tem como fundamentos:

$\mathrm{I}$ - o respeito à privacidade;

(...)

IV - a inviolabilidade da intimidade, da honra e da imagem;

(...)

VII - os direitos humanos, o livre desenvolvimento da personalidade, a dignidade e o exercício da cidadania pelas pessoas naturais.

Art. $3^{\circ}$ Esta Lei aplica-se a qualquer operação de tratamento realizada por pessoa natural ou por pessoa jurídica de direito público ou privado, independentemente do meio, do país de sua sede ou do país onde estejam localizados os dados, desde que:

I - a operação de tratamento seja realizada no território nacional;

II - a atividade de tratamento tenha por objetivo a oferta ou o fornecimento de bens ou serviços ou o tratamento de dados de indivíduos localizados no território nacional; ou (Redação dada pela Lei $n^{\circ} 13.853$, de 2019)

III - os dados pessoais objeto do tratamento tenham sido coletados no território nacional.

$\S 1^{\circ}$ Consideram-se coletados no território nacional os dados pessoais cujo titular nele se encontre no momento da coleta.

$\S 2^{\circ}$ Excetua-se do disposto no inciso I deste artigo o tratamento de dados previsto no inciso IV do caput do art. $4^{\circ}$ desta Lei.

(...)

Art. 17. Toda pessoa natural tem assegurada a titularidade de seus dados pessoais e garantidos os direitos fundamentais de liberdade, de intimidade e de privacidade, nos termos desta Lei.

Art. 18. O titular dos dados pessoais tem direito a obter do controlador, em relação aos dados do titular por ele tratados, a qualquer momento e mediante requisição:

I - confirmação da existência de tratamento;

II - acesso aos dados;

III - correção de dados incompletos, inexatos ou desatualizados;

IV - anonimização, bloqueio ou eliminação de dados desnecessários, excessivos ou tratados em desconformidade com o disposto nesta Lei;

$\mathrm{V}$ - portabilidade dos dados a outro fornecedor de serviço ou produto, mediante requisição expressa, de acordo com a regulamentação da autoridade nacional, observados os segredos comercial e industrial; (Redação dada pela Lei $n^{\circ} 13.853$, de 2019) 


\begin{abstract}
VI - eliminação dos dados pessoais tratados com o consentimento do titular, exceto nas hipóteses previstas no art. 16 desta Lei;

VII - informação das entidades públicas e privadas com as quais o controlador realizou uso compartilhado de dados;

VIII - informação sobre a possibilidade de não fornecer consentimento e sobre as consequências da negativa;

IX - revogação do consentimento, nos termos do $\S 5^{\circ}$ do art. $8^{\circ}$ desta Lei.
\end{abstract}

Patrícia Peck Pinheiro (2020, p. 142) pondera no sentido de que “A LGPD destaca que o tratamento de dados pessoais deve observar a boa-fé e possuir finalidade, limites, prestação de contas, garantir a segurança por meio de técnicas e medidas de segurança, assim como a transparência e a possibilidade de consulta aos titulares".

A Lei Geral de Proteção de Dados Pessoais fala, por exemplo, na necessidade de anonimização dos referidos dados, conceituando o dado anonimizado, no inciso III, de seu art. $5^{\circ}$, como "dado relativo a titular que não possa ser identificado, considerando a utilização de meios técnicos razoáveis e disponíveis na ocasião de seu tratamento" e a anonimização no inciso XI, do mesmo artigo, como sendo “utilização de meios técnicos razoáveis e disponíveis no momento do tratamento, por meio dos quais um dado perde a possibilidade de associação, direta ou indireta, a um indivíduo".

O que seria, contudo, um meio técnico razoável e disponível? É de se indagar, realmente, se não teria sido mais adequado que se debruçasse o legislador por estabelecer patamares mínimos para que se considerasse como respeitada dita anonimização.

Nesse ponto, como exemplo, por mais que se trate de uma previsão legal explícita, a qual, do ponto de vista teórico, revela-se absolutamente escorreita, acaba ela, sob a ótica prática, por deixar largo campo de subjetivismo para uma questão que se mostra concreta e que faz parte do cotidiano de todos.

Sustenta-se a concretude da referida questão na medida em que, como já citado, a utilização de redes sociais e de "smartphones" se mostra cada vez mais difundida, afastandose, cada vez mais, do plano de uma utilidade ou comodidade, e se aproximando, consequentemente, do plano da necessidade humana.

Aliás, merece menção o fato de que, dentre outros autores, Valério de Oliveira Mazzuoli (2015, p. 219-240) sustenta há alguns anos que o "direito a estar conectado" ou " de livre acesso à internet" se trata de um direito comunicativo de caráter fundamental, o que parece se intensificar no atual contexto de pandemia, que exige o distanciamento social e aumenta a 
importância de se estar conectado como um pressuposto para o exercício de vários outros direitos.

Por mais que se reconheça a existência de avanço no disciplinamento da matéria, ainda parece haver situações que mereçam cuidado mais detalhado e específico, mormente diante do fato de que se tem revelado claramente insuficiente o sistema de resposta legal a eventuais danos decorrentes de ofensa à privacidade, bem como no que tange, especificamente, à própria constatação (ou não) da referida ofensa, o que pode gerar cenário de insegurança jurídica e de menoscabo à intimidade e privacidade dos cidadãos.

Desse modo, embora não possa haver a pretensão de esgotamento, em absoluto, no plano legal, de toda e qualquer questão envolvendo o tema da privacidade nos meios digitais, afigura-se possível, e desejável, que haja um maior cuidado, por parte do legislador nacional, na disciplina da proteção a referido direito, que, como visto, é da mais alta relevância, possuindo, inclusive, estatura constitucional de direito fundamental de eficácia imediata e com natureza de cláusula pétrea, por força do comando dos arts. $5^{\circ}, \S 1^{\circ}$ e $60, \S 4^{\circ}, \mathrm{IV}$, da Constituição da República.

\section{CONSIDERAÇÕES FINAIS}

Os mecanismos, hoje existentes, de coleta de dados, seja em redes sociais, seja na própria Internet como um todo, representam, em boa medida, uma evolução de um processo que já se potencializava, sobretudo a partir do surgimento e da expansão do "spamming", passando pela popularização das redes sociais e dos "smartphones", e culminando com a publicidade direcionada a partir da coleta de dados pessoais.

Nesse sentido, o Direito, inclusive o brasileiro, vem tentando acompanhar esse movimento, mediante evolução da disciplina positivada, como se percebe a partir do advento do Marco Civil da Internet e da Lei Geral de Proteção de Dados Pessoais.

Contudo, nada obstante se reconheça alguns méritos dos referidos diplomas legais, ainda nos parece ser insuficiente e, por conseguinte, ineficiente a disciplina legal brasileira, gerando potenciais incertezas, que se traduzem, entre outros pontos, na indesejável presença de insegurança jurídica. Dentre outras indagações feitas no decurso do trabalho, destaca-se, por exemplo, a dúvida de quais seriam os meios razoáveis e disponíveis a que fazem menção os incisos III e XI do art. $3^{\circ}$ da Lei Geral de Proteção de Dados Pessoais. 
$\mathrm{Na}$ mesma medida em que parece se valer o legislador de lógica semelhante à de que se valeram Miguel Reale, e os demais membros da comissão elaboradora do Anteprojeto de Código Civil, no que tange à adoção do princípio da eticidade, que dá margem à utilização de conceitos jurídicos indeterminados e de cláusulas abertas, faz-se presente, nesse ponto, um aparente paradoxo, na medida em que, não obstante isso possa se motivar numa preocupação de evitar o "engessamento" da lei, acaba-se, de outro lado, por se fazer presente grave insegurança jurídica, envolvendo tema bastante sensível, o que pode implicar, entre outros pontos, proteção deficitária ao direito de privacidade no contexto do meio ambiente digital.

Por mais que se reconheça a existência de avanço no disciplinamento da matéria, ainda há situações merecedoras de cuidado mais específico, mormente diante do fato de que parece absolutamente insuficiente o sistema de resposta a eventuais danos decorrentes de ofensa à privacidade, bem como no que tange, especificamente, à própria constatação (ou não) da referida ofensa, o que pode agravar o referido cenário de insegurança jurídica.

Desse modo, embora não seja factível uma pretensão de esgotamento absoluto no plano legal dessa temática, afigura-se possível (e desejável) que haja um maior cuidado, da parte do legislador, quanto ao direito à privacidade, que, como visto, é de grande importância, na medida em que possui, inclusive, estatura constitucional de direito fundamental e, portanto, de cláusula pétrea.

Desse modo, conclui-se no sentido de ainda se mostrar insuficiente a disciplina legal a respeito da matéria, a ensejar cenário de insegurança jurídica e de proteção deficitária à privacidade no meio ambiente digital, em descompasso com a relevância do bem jurídico e direito fundamental envolvido.

\section{REFERÊNCIAS BIBLIOGRÁFICAS}

ALMEIDA, Tiago Agostinho de. SPAM = do surgimento à extinção. 2010. 100f. Tese (Doutorado). Universidade Estadual de Campinas, Faculdade de Engenharia Elétrica e de Computação, Campinas, 2010.

COLLIER, Paul. O Futuro do Capitalismo: enfrentando as novas inquietações. Porto Alegre: L\&PM, 2019.

DALY, Karen. Internet Hoaxes: Public Regulation and Private Remedies (2000 Third Year Paper). Cambridge: Harvard, 2000. Disponível em <http://nrs.harvard.edu/urn3:HUL.InstRepos:8965617>. Acesso em: 19 jun. 2020. 
FIORILLO, Celso Antonio Pacheco. Fundamentos constitucionais do meio @mbiente digit@1 na sociedade da informação. In: OOSTERBEEK, Luiz. AHMED, Flávio. Congresso LusoBrasileiro de Interfaces Multidisciplinares do Direito para a gestão integrada do território. Tomar: Instituto Terra e Memória, 2014. Disponível em <http://www.pacadnetwork.com/itm/images/sampledata/Domeniu/AREA_DOMENIU_Vol05 _Compressed.pdf\#page=70>. Acesso em: 19 jun. 2020.

GOMES, Marcelo Kokke; OLIVEIRA, Marcio Luiz de. Digital Pollution: Going Beyond The Limits Of Virtual. Revista Jurídica. v. 3, nº 52, Curitiba. 2018, p. 55-84.

MAZZUOLI, Valério de Oliveira. Direitos Comunicativos como direitos humanos: abrangência, limites, acesso à internet e direito ao esquecimento. Revista do Direito de Língua Portuguesa. Ano III, no 6, Lisboa: Jul-Dez de 2015, p. 219-240.

NAVES, Bruno Torquato de Oliveira. SÁ, Maria de Fátima Freire de. Direitos da Personalidade. Belo Horizonte: Arraes, 2017.

NAVES, Bruno Torquato de Oliveira. Direitos de Personalidade e Dados Genéticos. Belo Horizonte: Escola Superior Dom Helder Câmara, 2010.

NAVES, Bruno Torquato de Oliveira. O Direito pela perspectiva da Autonomia Privada. Belo Horizonte: Arraes, 2014.

PINHEIRO, Patrícia Peck. Proteção de dados pessoais: comentários à Lei n. 13.709/2018 (LGPD). $2^{a}$ ed. São Paulo: Saraiva Educação, 2020.

RÁO, Vicente. O Direito e a Vida dos Direitos. $7^{a}$ ed. São Paulo: Revista dos Tribunais, 2013.

REALE, Miguel. Visão geral do Novo Código Civil. In: GAMA, Décio Xavier. Revista da Emerj. Emerj debate o Novo Código Civil. Rio de Janeiro: Escola da Magistratura, 2003. Disponível em <https://www.emerj.tjrj.jus.br/revistaemerj_online/edicoes/anais_onovocodigocivil/anais_esp ecial_1/Anais_Parte_I_revistaemerj.pdf>. Acesso em: 19 jun. 2020.

THIBES, Mariana Zanata. A vida privada na mira do sistema: a Internet e a obsolescência da privacidade no capitalismo conexionista. 2014. 190f. Tese (Doutorado). Faculdade de Filosofia, Letras e Ciências Humanas, Universidade de São Paulo, São Paulo, 2014. 